\title{
The After-School Programme: An Arena for Interaction with Others through Body Movements in Play
}

\author{
Knut Løndal, Oslo University College \\ E-mail: knut.londal@lui.hio.no
}

\section{Abstract}

This article investigates how the body movements in children's play are related to their interaction with others. Qualitative material was gathered from close observation and qualitative research interviews among eight- and nine-year-old children in an after-school programme (ASP) in Norway. The theoretical perspective is phenomenological. The study shows that body movements in the children's self-chosen and child-managed play outdoors are extensive and arise from play situations where children spontaneously seek interaction with others. Such bodily interaction occurs largely in small groups of best friends or in larger groups that come together as the participants undertake the same activity. The children's body movements play a significant role in their interaction with others and can be interpreted as a fulfilment of their seeking such interaction. Based on the findings, it is recommended that self-chosen and child-managed play outdoors be encouraged in the ASP. While extensive body movements arise out of interaction in play, the play may also contribute to the children's health and development. The ASP can fill a complementary function to institutions with structured and adult-controlled activities.

\section{Introduction}

Societal changes in recent generations have resulted in children of early school ages spending much of their day in institutions (Frønes, 1998; Moss, Dillon, \& Stathan, 2000; Näsman, 1994; Prout, 2005; Zeiher, 2001, 2002)—including the school, the after-school programme (ASP), and leisure-time organisations. Based on the argument that physical activity positively affects children's health and development (Blair, Clark, Cureton, \& Powell, 1989; WHO, 2002, 2004), concern has been expressed whether children have sufficient activity within the institutionalised day. This has resulted in increased research into children's activities. The studies have often been based on the perspectives of biology and physiology, which focus on the effect of the child's physical activities upon formulated recommendations about intensity, frequency, and duration (Ekelund, 2002). "Physical activity" is commonly defined as "any bodily movement produced by skeletal muscles that results in energy expenditure” (Caspersen, Pereira, \& Christenson, 1985, p. 126), a definition that illustrates a close connection to physiology and natural science. A review 
of 26 studies from several countries worldwide show that children 12 years or younger attain two hours of daily physical activity (Epstein et al., 2001). This is important for interpreting and evaluating physical health benefits, but such research incorporates the child's own experience with their activities to only a minor extent.

In Norway, the ASP is a public institution that is administered by the school or the municipality outside of normal school hours. It is a voluntary programme for children in the first four years of schooling and is organised as closely related to the public schools. Physical activities in schools in Norway are related to the National Curriculum for Physical Education (PE), but also appear in various situations and places beyond the formal curriculum. Such activities can be defined as extra-curricular PE when initiated or organised by professionals (Green, 2008; Penney \& Harris, 1997). Many activities in the ASP are initiated by the staff and can be regarded as extra-curricular PE. In contrast with the sportisation of extra-curricular PE in other European countries (Green, 2008), the ASP staffs in Norway are expected to stimulate selfchosen and child-managed activities in the children's "leisure time." The Norwegian Education Act specifies that the programme shall provide the opportunity for play, cultural, and leisuretime activities and provide the children with care and supervision (KD, 2009). There are no formal educational objectives associated with ASP and no governmental requirements for formal pedagogical education for staff. This has resulted in a significantly higher number of children per employee in ASP than in primary school, with only a minority having pedagogical education (Kvello \& Wendelborg, 2002).

Results from a survey conducted in Oslo in 2003 show that body movement in children's self-chosen activity during ASP time is extensive (Løndal \& Bergsjø, 2005). This article is based on a fieldwork carried out in Oslo in 2007, and the aim is to investigate how the body movement in children's play is related to the child's interaction with others. The article focuses on children's life-worlds and emphasises their own experience of the activities. For this reason, the concept of "body movement" is used instead of physical activity. Body movement can imply changing positions and thus can be designated as locomotory movement (Gallahue \& Ozmun, 2006) - examples of which are running and climbing. Body movement where the child undertakes balancing exercises or engages in special physical postures can be characterised as stabilising. A third variant comprises manipulative movement, which is related to unique objects or substances; for example, when the child plays with a skipping rope or plays in the sandpit. In this article, activities where the child is sitting or standing with minor movement are excluded from the concept of body movement. When focusing on the children's own experiences of body movement, it is necessary to find an alternative to the strict biological understanding of the body that emphasises physiological research. Theoretical standpoints that consider human consciousness as embodied offer an alternative understanding. Such a theoretical perspective is introduced below.

\section{Theoretical Perspective}

The article is based on a phenomenological standpoint and is written with a background in a study of a life-world approach. The intent is to investigate children's experiences as they are lived in real-life situations (van Manen, 1990). The theoretical perspective is based on MerleauPonty's understanding of the human being and its relation to others.

Merleau-Ponty (2002 [1962/1945]) refers to the human being as an embodied subject that is 
closely related to the world: "[M]an is in the world, and only in the world does he know himself" (p. xii). Consciousness and understanding are embodied, something that establishes the basis for spontaneous actions that are adapted to the world. That world within which the individual lives is not merely physical, but is also social and cultural and includes experiences shared with others. The subjectivity does not exist inside the child, but rather in an inter-world of shared meanings: "Thus it is in this conduct, in the manner in which the other deals with the world, that I will be able to discover his consciousness” (Merleau-Ponty, 1964, p. 117). Thus, children express their experiences in a shared world where they can understand each other. Expressions can take form as actions, gestures, facial expressions, and language, and are part of an initial precommunication that is understood spontaneously (Busch, 2008; Merleau-Ponty, 1964). It is worth noting that Merleau-Ponty (2002) speaks about a bodily intersubjectivity where human beings can only understand themselves and others as living bodies:

Between my consciousness and my body as I experience it, between this phenomenal body of mine and that of another as I see it from the outside, there exists an internal relation which causes the other to appear as the completion of the system. The other can be evident to me because I am not transparent for myself, and because my subjectivity draws its body in its wake. (p. 410)

According to Merleau-Ponty (1964), the child's perception of others emerges early in life. The infant does not grasp the exact meaning in emotional expressions presented by others, but facial expressions can be perceived at a very early age. In "The first smile of the child" Buytendijk (1988) delivers a good phenomenological example of such an early, intuitive, reciprocal contact. Merleau-Ponty (1964) rejects the classical explanation, which claims that the infant child's reprisal smile is a consequence of a complicated process of visual perception, feelings, projections, cognition, and motor action:

The consciousness I have of my body is not the consciousness of an isolated mass; it is a postural schema. [T]he experience I have of my own body could be transferred to another much more easily than the cenesthesia of classical psychology, giving rise to what Wallon calls a "postural impregnation” of my own body by the conducts I witness. (pp. 117-118)

This opens the way for a reciprocal process of communication where the perception of my own body can be transferred to the other, and where my body-schema can understand the bodyschema of the other immediately and spontaneously. The communication consists of a bodystructure with an interchange between my meaningful actions and the other's meaningful actions (Merleau-Ponty, 1964; Rasmussen, 1996), and provides a basis for tacit face-to-face or body-tobody contact.

Gallagher (2001, 2006) takes his point of commencement in Merleau-Ponty’s understanding of intersubjectivity. He claims that "the understanding of the other person is primarily neither theoretical nor based on an internal simulation, but is a form of embodied practice" (Gallagher, 2001, p. 85), and that "There is ... a common bodily intentionality that is shared across the perceiving subject and the perceived other" (p. 87). He uses the concept of "primary intersubjectivity" when referring to bodily, emotional, and perceptual processes that determine the child's ability to comprehend others through observation, including the child's ability to see meaning in others' actions. Correspondingly, the concept of "secondary intersubjectivity" is used 
when the child begins to interact with others in social situations. This is described as an embodied phenomenon that does not disappear during later development, but is strengthened through various intersubjective experiences (Gallagher, 2006). In this article, the concept of intersubjectivity is used in accordance with Merleau-Ponty's and Gallagher's.

Participation in the ASP involves a variety of situations where the children interact in large or small groups during play and where body movements are part of the interaction. In this article, their body movements in such situations are described and discussed based on the theoretical perspective introduced above.

\section{Method}

The phenomenological perspective requires information to be gathered in the life-world. The researcher has to evolve a way of looking at the subjects in concrete real-life situations (Bengtsson, 2006). For this reason I was engaged in following the children in an ASP group during an extended period. During this four-month period in autumn 2007, I assembled qualitative material. Merleau-Ponty (2002) argues that the body and language are complementary forms of expression and communication. In this study, qualitative material was gathered from the children's lived experience that captured these interlinked components, and two complementary methods were used-close observation (van Manen, 1990) and qualitative research interviewing (Kvale, 1996).

\section{Participants}

The aim of the project was to contribute to an understanding of the children's body movements in play and not to compare institutions. For this reason, the investigation was delimited to a single ASP that was organised related to a single public school. Due to the need to be able to recall experiences and articulate them, the study was concentrated on the upper two age groups who were permitted to attend the ASP: children in the $3^{\text {rd }}$ and $4^{\text {th }}$ grades in school.

During the period of the study, 41 percent of the children in the $3^{\text {rd }}$ grade and 47 percent of the children in $4^{\text {th }}$ grade in the selected school followed the ASP, for a total of 40 children. Permission was sought from the parents and the children concerning participation in the study. Parents of four children had reservations about participation: consequently, information was gathered from 36 children, 19 of whom were born in 1998 and 17 in 1999; 22 girls and 14 boys participated. The children followed the ASP between two and three hours each day.

\section{The Context}

The ASP, which is the basis of the study, is located in the suburbs of Oslo. The associated building comprises a recreation room with a dining area, a small computer room, a reading room, and a cloakroom. All the rooms are available to the children during ASP hours. In front of the entrance to the ASP building are a flat asphalt place and a large sandpit. Immediately to the side of the main building is a small playhouse surrounded by trees suitable for climbing: the children refer to this as "The Climbing Area.” Otherwise, the building is surrounded by a slope that leads 
down to a small valley. Approximately half the area comprises grass; the rest is trees and rugged terrain. The ASP area does not have traditional play apparatus.

A peripheral part of the school's play area is located in the immediate vicinity of the ASP site and is available to the ASP children. Here is "The Bunker," as the children call it, which is an area for ball games covered with artificial grass and surrounded by a fence. A gravel football pitch is also located nearby. On the edge of the pitch are various types of swings and "The Wheel." 1

The children are offered full freedom to move from one area to another, but they have to tell the staff members if they want to go to the school's play area. They can also choose whether they to be indoors or out. However, irrespective of weather and temperature, the children have to be outdoors for a period of ASP time.

\section{Gathering Qualitative Material}

Using close observation to gather material, one attempts to break through the researcherinformant distance (van Manen, 1990). Instead of observing the informant from the outside, one attempts to enter the life-world through direct participation. The observations were linked to six places within the ASP area that emerged as particularly interesting with respect to body movement: the asphalt place, the sandpit, The Climbing Area, The Bunker, The Wheel, and the recreation room indoors. The choice of places for observation was based on a two-week study during ASP hours in August 2007.

Video and sound recordings were used to register situations and events. Focus was concentrated on one of the selected places each day, and the observations were filmed or noted when one or more of the 36 children were present at that place. A main camera could be zoomed and the focus varied; a supplementary camera was used to record the general situation of the place under observation. The two cameras had attached microphones. Up to one hour was recorded each day. Parallel to the recording, field notes were made.

After the observations were concluded, nine children comprising five girls and four boys were selected for individual qualitative research interviews. The interviews were intended to provide depth to situations and events that had emerged in the observations. Prior to a detailed planning of the interview and selection of the subjects to be interviewed, the field notes and video recordings were closely examined. Specific themes were identified that were to be closely followed up. The themes were related to the child's body movements at specific places, the child's interactions with other children, and particular events that affected the child's body movements. The children selected for interview had been involved in particularly interesting situations related to these themes. Both girls and boys from the two relevant age groups were selected, and it was taken into account that they should represent a variety of preferred activities. Against this background, valuable supplementary information was expected to be obtained. In line with Kvale's (1996) recommendations, the interview was given the character of a one-to-one conversation where the child could relate his or her own experiences to relevant themes. Prior to the interview, an interview guide was prepared with a list of themes to be covered, together with proposals for introducing and follow-up questions. During the interviews, the sequence and structure of the questions could be changed.

The interviews were carried out with one child at a time in a room with which they were well acquainted. The interview commenced with situations in which the child had participated and been videotaped. These were edited to form a four-minute film for each individual, which 
was shown during the course of the interview and provided a basis for the conversation. During the interviews, the children were asked about my interpretations of specific situations from the observations. Several times I also pronounced interpretations of the child's statements and asked whether they had been correctly understood. The interviews were videotaped and soundrecorded.

\section{Transcription and Analysis}

This article distinguishes between gathering and analysing qualitative material from the children's lived experiences but, in line with van Manen (1990), the two acts are not considered separable processes. Since the gathering involved choices and reflections, an analysing process had begun already in the field. After the material had been gathered, a further qualitative analysis was conducted. This analysis included a systematic reading of the transcript by dwelling on phenomena studied, followed by a description of recurrent themes.

To ensure that the qualitative material was suitable for further analysis, it was transcribed. The material comprised the video and sound recordings from 22 hours of observations, five hours of video and sound recordings from the interviews, and 156 pages of handwritten field notes.

The transcriptions of the interviews were written in note form such that the significance of the conversations emerged. The interview recordings showed that there was supplementary information in the form of non-verbal gestures. To include these gestures in the analysis, the transcript notes were made in two columns - the spoken word in the left column, and the nonverbal signals described in the right. Examples will be given in the presentation of the findings. The recordings from the observation period were also transcribed and prepared for analysis.

In the further analysis, I used a method inspired by the structure of descriptive phenomenological analysis (Giorgi, 1985). The interview transcriptions, the transcribed situations from the video recordings, and the field notes were included in the process. Through a stepwise analysis comprising four chronological sets of written notes, I moved from 1) a basic description, via 2) localization of the meaning units and 3) incorporation into a theoretical perspective with relevant professional terminology, to 4) a synthesis of the meaning units to a consistent text where the phenomena studied emerge. It is important to emphasise that I do not consider my writings to be pure description. Each stage of the process included interpretations, and, in that sense, the process can be seen as interpretive or hermeneutic-phenomenological (van Manen, 1990).

During the process of transcription and analysis I tried to bracket own beliefs, and focused on finding cases that did not conform to preconceptions. The analysis was also discussed with two academic supervisors during the process, who challenged me to provide solid evidence for any interpretations.

\section{Findings and Discussion}

The results of the study will be introduced as selected situations from close observation outdoors and presented in the voices of the interviewed children. As a result of the analysis of the qualitative material, and based on the significance in relation to the entirety, specific situations 
are introduced that show the characteristics and import of body movements in the children's play. The examples include boys and girls in both age groups. Importance is attached to presenting situations that show how the children's body movements arise from a variety of everyday situations in the ASP. As a result of the analysis, the following themes appeared as typical for situations where body movements emerged: 1) Self-chosen and child-managed play, and 2) interaction with others.

\section{Self Chosen and Child-Managed Play}

The following description was written in the field notes on a September day:

I am located on a small hill where I can observe all the children who are outdoors. Two boys are swinging in the car-tyre swing, some girls are using the bird-cage swing, a large group of children are playing football on the gravel area, two girls are role-playing in one end of the gravel area, four girls are climbing in a tree, three girls are playing with The Wheel and one girl is sitting alone on one of the swings in the gravel area.

All the children in the area are engaged with play that includes one or another form of body movement. Such extensive bodily activity is typical of the ASP time during the observation period. As described, the observations were linked to five locations outdoors and one location indoors. Most of the observed body movements occurred outdoors, which corresponds with findings about activities in four ASPs from an earlier study (Løndal \& Bergsjø, 2005).

Jennifer is a nine-year-old girl in the ASP group. In the interview, she clearly expresses how important it is that the ASP provides an opportunity for activities that include body movements:

Interviewer: Tell me what you usually do at ASP.

Jennifer: $\quad$ When I am at ASP I like to play football, we play tag and hide and seek, and sometimes I play with a skipping rope.

Interviewer: OK. Many different activities?

Jennifer: $\quad$ Yes, but for me it is mostly football (smiles). It is important that we can do such things here at ASP (nods energetically).

Interviewer: How would it be if you could not do such things?

Jennifer: $\quad$ Oh, that would be boring (looks disappointed).

She uses the term "boring” when she refers to negative experiences and unhappy situations, and this is typical for the children studied. Activities in their everyday life are attached to different moods of being; they are placed on a continuum between boring and fun. All the children interviewed agree that play that includes body movement is an important facet in making sure the ASP does not become boring. It is worth noting that such statements are related directly to activities in the ASP. Several children gave different impressions when they talked about activities in other situations in life-for example about activities at school or at home. Many of 
the children reported that they enjoy the adult-managed work at school, and some of the children said that they really like to do homework when they are at home. However, at ASP such sedentary activities are considered boring. Jennifer's conduct during the interview indicates that body movements are closely associated with emotional circumstances. The non-verbal gestures emphasise their range of emotions, from bored to full of enjoyment, and differ from one activity to the next. The physical-emotional association is also manifested many times during the observations. The following example illustrates a positive emotion and is taken from a playsituation involving The Wheel.

Eight-year-old Rebecca plays on the Wheel, and takes off from the top level of the start ramp. She carries an erect body posture for half the length of the run. She then releases her hold slightly and extends her body just as the wheel reaches the end-point. She makes a violent swing and stands upside down shouting "wow!" and laughs gleefully as she makes her way back. As she hops off The Wheel, she appears happy and enthusiastic.

Rebecca's bearing and shouts when playing on The Wheel seem to be expressions of pure joy. In the interview she responds to this situation: "I feel it is so fun! I feel like I have lots of butterflies in my stomach.” Buytendijk (1988) refers to a physical-emotional relationship in association with human movement, and states that such an alliance is particularly evident as the movement becomes the expression of "the joy of being in the world" (p. 15). This seems to fit well with the quoted situation where Rebecca is playing on The Wheel. The actual self-chosen body movement is a positive physical-emotional experience, and puts her in a positive mood of being.

Nine-year-old Elaine emphasises that the activities must be self-chosen and child-managed not to be boring:

Interviewer: Where do you prefer to stay when you are together with friends?

Elaine: $\quad$ Actually, I like it best when we are outdoors and around the ASP building. Elsewhere, the adults decide what to do, and it easily becomes a bit boring. It is important for me to play what I want together with my friends. I do not like to be forced to (responds fast and nods enthusiastically).

Interviewer: As long as you can decide yourself?

Elaine: $\quad$ No, it is not only me who decides ... but I want to play something that I want together with my friends (smiles and looks selfconfident).

Elaine prefers self-chosen play during the ASP time. However, she states that she does not decide by herself; other children are included in the decision. The choice of activity seems to emerge from an interaction between her friends. Other children are a part of what she perceives as her own decisions. This applies to not only Elaine. The children interviewed simply do not want to be told exactly what to do in the ASP time; they want self-chosen and child-managed activity, and self-chosen seems to mean chosen in interaction with other children.

The adult members of the ASP staff are not to the same extent included in the children's choice 
of activity. During the observation period there are only two adult-controlled activity sessions outdoors. Even though the children appear to enjoy it when someone in the ASP staff participates and manages activities, they tend to drop out of these more quickly than in child-managed play. It seems like the children to a greater extent are so engaged in self-chosen and child-managed play that they forget about time and purpose than in adult-controlled activity. As Elaine, all the children use the word "play" for such "unboring" self-chosen and child-managed activities that put them in a positive mood of being. The children's use of the word "play" seems to be in accordance with Gadamer's (1989) phenomenological description of the concept. Play is not characterised by the activity as such, but rather by the player's positive physical-emotional mood of being when conducting the activity. Gadamer does not emphasise the player or her intentions, but rather focuses on play itself. The subjective expression is transposed from the playing subject over to the play itself. It is the play that is the subject. Self-chosen and child-managed play "places demands on" the player and the player allows herself to be swept away. The videorecordings reveal many examples where such play activities can last for almost an hour, and reveal that these have a spontaneous transition to other activities. This contrasts with the adultcontrolled activities where the majority of children drop out after just a few minutes unless the activity is "obligatory." However, the observation shows that groups of children often continue with play that originate from adult-managed activity, but independent of the adult person who initiated it. It seems like the mood of being that allows the children to be swept away by the play is more likely to emerge in child-managed situations than in situations where adults are in charge.

It is worth noting that the formulated vision for the present ASP is that the free choice of the child shall be the main rule. This also corresponds with important management documents for the Norwegian ASP (Haug, 1994; Øksnes, 2001). The staffs of Norwegian ASPs are expected to stimulate self-chosen activities in the children's "leisure time." This study indicates that the children appreciate this, and that body movements arise out of self-chosen and child-managed play as long as they spend time outdoors. Nevertheless, members of the ASP staff play an important role in initiating activity. Some of the observed places outdoors need appropriate equipment that stimulates the children's play. If the adults did not make such equipment available, a substantial decrease in the children's bodily play at the asphalt place and in The Bunker was observed.

\section{Interaction with Others}

In interviews the children were asked which social settings they prefer during ASP time. Jennifer's answer is offered as an example:

Interviewer: In the short video we saw you in different activities, sometimes alone and sometimes together with others. How do you like it best? To do activities together with others, or do you prefer to be alone when you are active?

Jennifer: I prefer to be together with others (answers quickly and spontaneously). Then I have someone to play with. It is boring to be alone (smiles and looks self-confident). 
Jennifer's answer does not seem to be incidental. The earlier quoted example from the field notes (cf. p. 7) may serve as an example; the situation is emphasised by intersubjective contact between the children. They interact in large or small groups dependent upon the activity in which they are involved. The observations in the ASP show broad variation in intersubjective situations in the children's play. In the quoted example (cf. p. 7), only one child was not engaged in play with another or a group: She was sitting alone on a swing on the gravel area. This does not mean that she was not involved with the others. The video shows that she just came from play together with the girls who were role-playing, and that she was engaged in intensely following the activities of the girls on The Wheel. As such, she was influenced by the other children. Switches between activities and groups of children are not unusual during the ASP time, but it is very rare that a child is alone over an extended period. This emphasises the children's propensity to seek activity together with other children when playing. The observed situations in the survey show that body movements with intersubjective contact are typical in the ASP, which interviews indicate is not incidental. It seems very important in all the interviews that body movement can occur together with other children. The fact that children seek body movement in play together with other children is a predominant feature during ASP hours. This can be seen in association with the concept of secondary intersubjectivity, as described by Gallagher (2006): The children's interaction is strengthened through variable intersubjective experiences. In situations with body movements, a distinction is made between two main categories of interaction: Situations where the child's demonstrative expressions in the presence of others are predominant and situations where shared activity seems to be the most important. Both of these categories can be interpreted as interaction, as common situations with intersubjectivity (ibid).

\section{Expression.}

When playing at the observed places the children often shout "Look at me!" The following example is taken from activity on The Wheel.

Rebecca is ready to jump from the top level of the start ramp. While she is preparing to jump, the other girls are discussing anything else but her activity. Rebecca wants attention and asks: "Do you think I dare take off from here?" "Yes, of course. Everybody knows that," Sophie replies, a bit irritated. Then, Rebecca turns directly toward Jennifer. "Jennifer, watch me," she says. She waits until Jennifer actually is watching her. Then she leans to the side with her body extended, getting a soft start with a tight rope.

Rebecca demands attention from the other children to show what she is able to do. This is not just anything - it is an activity that commences high up, with considerable speed and with precise physical action. It is calculated as an act of daring among the ASP children. SheetsJohnstone (1999) gives the movement the honour for the sense of "I can." This seems to be in accordance with that which Rebecca expresses on the start ramp. Through the repeated movements on The Wheel, Rebecca discovers what she can do with her body on the apparatus. The movement appears to result in a typical feeling of excitement and fascination that she wants to share with others, simultaneously receiving acknowledgment for her feat. Her "significance of movement" is associated with the attention by others (Smith, 2007; van den Berg, 1952). This situation can be interpreted in two different ways. On the one hand, Rebecca's active search for 
attention may be explained as a way to get feedback directly related to the performance; to strengthen her "I can". On the other hand, it may be explained as a way to position her in relation to other children in the vicinity. The others' attentions toward the movement she is executing on The Wheel may be important in gaining acceptance and recognition. Seeking understanding and recognition seem to be an important element of the child's body movement in the ASP. As such, Rebecca's conduct may show a strong desire to reveal her movement solution to her peers and the adults in the vicinity and to receive an acknowledgement of these.

One example where children who are participating in the ASP seek recognition by an adult is given in the following example.

Eight-year-old Sophie is preparing to take a trip on The Wheel. When she is ready, she sees Linda (a member of the ASP staff) passing by on a nearby path. She shouts loudly: "Hey, Linda. Look at me!" She then undertakes a strenuous motion on the apparatus. "You are so clever. I am surprised that you dare," Linda responds. "Look at me too, Linda!” Rebecca calls. Linda stops and watches. Rebecca then makes a breathtaking trip on The Wheel. Linda applauds and smiles in acknowledgement. When Rebecca has finished the trip, Linda waves, and goes on her way. The girls continue with their testing and barrierbreaking activities.

Linda's recognition of the children's activity appears to be important for carrying out the activity. She takes time to watch their efforts, and through comments and gestures acknowledges their choice of activity, including their daring.

The adults' approval of the children's activities appears to be important where the children demonstrate their physical skills in front of the staff. In their account of child-oriented communication, Fattore and Turnbull (2005) draw upon the work of Merleau-Ponty, stating that the inter-world of shared meanings creates a space to understand others and the social world, and that "Children, therefore, enter the 'intersubjective order' as active participants, providing a basis upon which children and adults can understand each other” (p. 52). Merleau-Ponty (1964) emphasises that the development of the self involves experiences through which children recognise themselves via the reactions of significant others (Fattore \& Turnbull, 2005). According to this viewpoint, the child should be considered as an authority in respect to her own experiences and actions. Linda clearly exhibits the will to grant the children authority. Her attachment to the importance of daring as something positive appears to increase their desire to conduct more experiments. This is a way the ASP staff can encourage body movement in selfchosen and child-managed play.

The attention of peers toward the expressive movement appears to be equally as decisive for the child that someone observes as to who observes. Consider the previous example of Rebecca on The Wheel: when her best friend ignores the invitation to watch, she quickly turns to another girl. As soon as she has ensured that someone will watch her, she carries out the exercise. Thus, gaining acceptance and recognition from a special friend or from someone who is considered particularly important among the children does not seem to be the most important aspect of this situation. What she is seeking seems to be the intersubjective interaction with other children as such. On this occasion the reactions she receives from the others appear to be more important than her expression to the others. An example from The Climbing Area shows the outcome when Roger's demand for attention is ignored: 
Roger is climbing in one of the trees in The Climbing Area. He moves to the roof of the playhouse, and from there he climbs over to another tree. He stops and looks for the other children. He shouts repeatedly to get attention, first to all the children in general, later to named individuals. None are responding, so he is standing motionless for a while. Then he jumps down and runs toward another place.

Roger is a newcomer to this ASP, and he tries out various movements in The Climbing Area. He wants someone to observe his climbing. When none are willing to observe, his movements are not carried out.

How can the strong desire of a child to be observed when carrying out particular movements be explained? As mentioned, Merleau-Ponty (2002) considers that there is an essential association between individuals. Meaning is in the expression; expression and meaning are inseparable values (Busch, 2008). When a child expresses with movement to the others, this can be regarded as a form of communication. Such bodily communication is especially clear among children. The first $10-12$ years of their life they communicate more directly and immediately through their bodies and body language than later in life (Adams, 2008; MerleauPonty, 2002). The child communicates her skills in a bodily manner in different places and wants acceptance for this. To ensure that someone reacts to this expression, a direct approach is made: "Watch me!" Before commencing the exercise, the child ensures that someone is watching. The other children spontaneously understand the meaning of the expression and communicate appropriate reactions through cheering, facial expressions, or gestures. The reactions will spontaneously be understood as a degree of acceptance and recognition. In this manner there is a dynamic mutuality in the interaction in that it assumes that the children know that they share something in common. In the child's self-managed activity in the ASP, such expressions and observations go both ways: Sometimes the child will be observed, other times she will be the observer.

It is interesting to note that the children studied do not hesitate to perform their body movements while others are looking. This applies to the expression of both habitual and nonhabitual body movement. One would perhaps expect Roger, who is an inexperienced climber at The Climbing Area, to try out various climbing movements alone before expressing to others. The material in this study does not show such a hesitation among the children. Regardless of experience and skill level, it seems to be important for the children to express their body movements to others. However, "demanded reception of expression" is most often seen in two categories of movement: 1) Movement that requires an element of daring - for example, high take-offs on The Wheel or challenging climbing in The Climbing Area-and 2) technical movement that requires precise adaptation to place, body, and equipment. Examples of this are the balancing exercises undertaken on the scooters and swinging a hoop around the waist. In this study, the expressions of movement that require daring are more manifest among girlssomething that breaches the stereotyped image of boys as the most vigorous. According to the findings in this study, the desire to exhibit one's skills and achieve recognition seems to be very strong among both girls and boys. However, the experience of carrying out such exercises is not as strong when they are not being observed. This clearly shows that the body movement in such situations is closely connected to the fact that the children want to communicate something about themselves to the others. If none are willing to interact by observing and responding to "the message" that in this circumstance is a body movement, the message will not be presented.

The communication that occurs in the situation of expression can be said to be two-sided. It 
is not important who is observing, but that someone does. For many children, however, it is important who shares in the execution of the exercise. A typical example is shown earlier in Elaine's statement in the interview (cf. p. 8); it has to be someone she considers a friend. "Friend" is a term or designation to which all the children interviewed attach importance in choice of activity, but different interpretations are given to the term. This also appears to affect the intersubjective interplay in which the body movement occurs. On one hand, there are strong bonds in pairs of best friends or small groups of close friends. On the other, we find larger groups of children with less defined relationships. These groups come together as the participants enjoy taking part in the same activities. In this article, I refer to these as "best-friends groups" and "activity groups." Observations at the selected places in the ASP show a clear connection between the genders and the types of group. I observed mostly girls in the first category and boys in the latter.

\section{Shared activities in best-friends groups.}

Elaine tells about friendship during the interview:

Elaine: $\quad$ My best friends are Cecilia, Ellen, Kari and Jane (she appears happy and satisfied).

Interviewer: Are these the girls you are mostly together with at the ASP?

Elaine: $\quad$ Yes, we are normally together. There are some who I am not together with very much-Anne and others. We are not unfriendly towards each other, but we don't play together. It is the others I play together with most (she explains quickly and looks directly at the interviewer.)

Interviewer: Why is this?

Elaine: I don't really know. It's like when you like being together with someone, you sort of understand each other. Then you play with them a lot as well (she smiles, a little uncertain at first, then she answers enthusiastically and with a serious facial expression).

Friendship relations are revealed in different forms of activity in the ASP. Elaine's statements strongly emphasise the mutual relationship between herself and her best friends. It is apparent that she attaches a different meaning to friendship than merely sharing the same activity. When she wants to do something active together with her best friends, demands are made on reciprocity; they have to understand each other. The close friends have a common desire to be together, and they find it quite natural to do activities that include body movements together. This corresponds with the concept of secondary intersubjectivity (Gallagher, 2006). Their ability to see meaning in the friends' actions is embodied, and they respond immediately and spontaneously. Elaine offers a compelling explanation of why she wants to play with someone before others: Best friends like to play together simply because there is a mutual and spontaneous understanding between them. If the mutual intersubjectivity does not flow easily, 
meaning in each other's behaviour will not be grasped spontaneously. Best friends seem to be selected among children who grasp meaning in each other's actions in a spontaneous way.

Some children are almost constantly together with one special friend or with a few close friends. Sophie and Rebecca are an example of such a pair. The relationship between them emerges in the following passage from the interview with Rebecca.

Rebecca: $\quad$ Most of all I like playing with Sophie. We play together the most, as she is my very best friend (she appears happy and satisfied).

Interviewer: Do you choose to do what Sophie does, or do you do what you want irrespective of what Sophie would like?

Rebecca: I do the same as Sophie, and sometimes Sophie does what I am doing. We decide a bit each-sometimes me, sometimes her (she responds quickly and looks self-confident).

Interviewer: Do you also play together with others, or is it just you two?

Rebecca: $\quad$ It is mostly us two, but sometimes when Dorothy is alone, we play with her. Or if May or Ida is alone, then we play with them (she looks as if this is a matter of course).

This is an example where the activity is based on reciprocity of affection in a close friendship. It appears that being together is more important for them than the activity in which they are engaged. The girls want to be together and then they agree about which activity. It is important for personal satisfaction that it is precisely that person they are with, and the choice of activity is determined as a mutual process. Sometimes this includes verbal discussion, other times the activity emerges spontaneously without speaking. According to Rebecca's statements in the interview, the relationship with Sophie does not exclude playing with others, but it is not incidental who the others are. Developmental psychologist Dunn (2004) emphasises reciprocity of affection when she defines children's friendship, and this seems to be in accordance with the understanding of friendship in the best-friends groups in the current ASP. Dunn maintains that friendship occurs only between two individuals at a time, but this is not seen in the interview with Rebecca. Dorothy, May, and Ida are also regarded as close friends, and it frequently occurs that one or more of these are with Rebecca and Sophie. Sophie and Rebecca engage in a range of activities but are virtually always together as a couple, either alone or together with other friends. Mutual tolerance and the will to adapt appear to be important within the group. In this particular pair of best friends, and in other groups of best friends that are observed in this study, the relationship between participants seems to be almost equal. The observation reveals many examples of children in best-friends groups expressing body movement to each other, but this seems to happen both ways. Investigations among younger children have shown how expression of body movement often occurs in a master-slave relationship, where one of the members of a pair of children dominates the other (Merleau-Ponty, 1964). The material of this study does not show examples of master-slave relationships between best-friends.

Should someone who is part of a closely-knit group of friends or a pair of best friends be on their own for one reason or another during the ASP hours, the intensity of the body movement is affected. Children who are otherwise active can become passive and dispirited in such situations; 
the activity becomes boring. Children finish at different times during the ASP hours and go home, resulting in some groups of friends breaking up. The last phase of the ASP day is often emphasised by individual children wandering around, wondering what to do. It is at this time that the children who are active and self-inspired look for quieter and adult-controlled activities indoors. Such situations reflect how the body movements are related to the interaction with other children in the best-friends group. The children seek interaction where they can communicate reciprocity of affection with their best friends. The study shows that such communication appears as body movements when the children have the opportunity for self-chosen and childmanaged play outdoors. The communication, that in these situations takes form as body movements, ceases when one part of the communication process disappears.

\section{Shared activities in activity groups.}

It is important for the children that activities that include body movement can occur together with friends, but different demands are placed according to how close these friendships must be. Nine-year-old Oscar and eight-year-old Eric spend much time in The Bunker, and they tell about activity and social relationships at this place:

1. Interviewer: What do you like best to do here at the ASP?

Oscar: Mostly, I play in The Bunker. That's where I like being best (responds quickly).

Interviewer: Is it important for you who else is there, or do you go there in any case?

Oscar: $\quad$ I go there anyway. I can play with several boys and girls (looks selfconfident).

2. Interviewer: What do you like to do here at the ASP?

Eric: $\quad$ I like to play football and hide and seek. Sometimes I play with a skipping rope. Football is what I like best to do (looks directly at the interviewer and nods).

Interviewer: How do you find it easiest to make friends and to get to know new children?

Eric: If, for example, they like playing football so perhaps I can be selected for their team. Then I can talk with them when we play. It is easiest to get to know each other when we do such activities together. Much easier than when we sit at the table and do homework (responds enthusiastically and looks directly at the interviewer).

These statements indicate that it is the activity that is decisive for their presence in The Bunker, and that it is the activity taking place there that leads to friendship. These boys don't emphasise 
reciprocity of affection as strongly as do members of the best-friends groups. However, the observation reveals that there are not only "pure" activities going on in the activity groups. Through actions, gestures, body language, shouting and speech the children communicate clearly how they react to their own and others' body movement and solutions.

The children who spend much time in The Bunker mention others who are there a lot as their closest friends or those whom they know best. As indicated in Eric's statement, friendship is a consequence of a preferred activity. They do not depend upon the presence of specific persons for participation in the activity to the same degree as children in the best-friends category. As long as there is activity at their preferred place, intensity is maintained. They have experienced that friendships can be developed through shared activity. Some scholars are sceptical to call relationships in groups larger than two or three as friendship (Dunn, 2004; Greve, 2007). Nevertheless, "friend" is the concept that the interviewed children who participate in such activity groups use. However, they don't emphasise reciprocity of affection as strongly as members of the best-friends groups. They participate in larger groups based on the activity taking place at that time. The most common activity in this group category is unquestionably football in one or another form.

As indicated in the quoted statements of Oscar and Eric, the group who keeps to The Bunker appears to be open regarding participation. Initially, anybody in the ASP can join in the game. Depending upon how many are present, the type of game varies. Discussions and negotiations in connection with choice of game and team members are often time-consuming, but rarely end in conflict as long as only the ASP children are present. Also in this group category, body movements play a significant role in creating interaction with others, but communicating reciprocity of affection is not the most important. The participants seem to regard the body movements in the play to be important enough in themselves. Nevertheless, friendships are developed through the interaction in such bodily play.

Observations and interviews reveal, however, that these activity groups are not completely open. In autumn 2007, Richard - a boy in the fourth grade-was a new member of the ASP. During the past three years this had been his third school and third ASP. In August, he had no friends here, and he sought activity and social contact in The Bunker. One early observation showed the problems he had gaining entry. The following description was written in the field notes:

Two small groups of ASP children are playing football in The Bunker; one group around each of the goals. Richard arrives and joins in the game together with the oldest children. Richard is ignored, and after just two minutes he withdraws from the game. He gets his own ball and plays with it. There are now three parallel activities: One group around each of the goals, and Richard alone in the middle. I note Richard's problems of joining the children's groups. Sometimes he is conflict-oriented and calls out some rude remarks to the other children. Then, after $a$ while, he asks if he can participate in a game with the children who are a year younger, but is rejected: "No, you are nasty towards us. You are rude in my opinion.”

To a certain extent, friendship is a condition for participation in the activity groups. Richard is not defined as a friend as understood by the children and not included. He withdraws from the group of similarly aged peers when he does not achieve a sufficient response. He is refused participation in the younger group because he is "nasty" and "rude." Richard engages in his own 
activities, but the exclusion affects his level of activity.

Richard mentions this in the interview. He gives the impression that he prefers to join in activities with others, but at the beginning of school year he must often play by himself. He speaks quietly and appears dejected when he relates this. He explains how difficult it is to acquire new friends when he changes schools. He thinks that it is easiest to gain new friends through activities such as football, and explains that he becomes disappointed and disconsolate if he is not allowed to participate. In observations from the early autumn it can be observed that the other children regard his attitude as anything but seeking friendship. He can barge into an activity group brusquely and frequently makes rude comments to the others, which results in exclusion from the activity - often in clear terms by the other children. This is an example of a child who acts in such a manner that the others cannot grasp his meaning. Gallagher (2001, 2006) attaches importance to an intuitive ability to see meaning in others' actions as a basis for intersubjective interaction. Richard wishes to participate in the activities to establish friendships, but his attitude is regarded as disrespectful. He does not understand the point of the others' reactions and regards his exclusion as unjust and unfair. This results in verbal or physical conflict, something the others consider nasty. This appears to be a vicious circle.

When we make a similar observation a month later, the situation has changed: Richard is now in the group that plays football. He is often the one who brings the ball, and his attitude is more relaxed. At times he may still "explode" negatively, which occasionally results in hard exchanges, although it does not lead to deep conflict and exclusion as previously. It appears that the others understand the meaning in his action, and that this has largely led to his acceptance in the activity group. Now he refers to some of the boys who play football as friends. This may suggest that the interaction in bodily play over an extended period has established a mutual understanding of one another's actions.

\section{Unsystematic interchange between main categories and activities.}

I have recognised two main categories of children's groups who engage in a variety of body movements in play: Best-friends groups and activity groups. However, not all ASP children can be placed within either of these categories. Some children switch rapidly and unsystematically between activities and groups, depending upon what activity appeals to them at the time. This occurs mainly close to the ASP building: On the asphalt place, in the sandpit, in the climbing area, and on the grass. Edward, Jim, and Amanda are active eight-year-olds who are constantly involved in one or another form of body movement. They may act as individuals, change between those they are with, and rarely keep up the same activity for any length of time. They switch quickly between activities with the tricycle, the scooter, the sandpit, climbing, the ropes, and so forth. They concentrate on what they are doing, but run quickly to another activity as soon as the opportunity arises. It appears that this occurs spontaneously, that they seize the opportunity for action wherever it arises. Gibson (1986) uses the concept of "affordance" for the relationships in an environment that offers the individual the opportunity for action. Affordances can be associated with the activity place, but are just as frequently associated with the children becoming aware of an activity in which other children are involved and engage themselves in this instead. This corresponds well with Merleau-Ponty's (2002) understanding of intersubjectivity. Through a transfer of body-schema, the child can understand the action of the other immediately. The other's action is part of the pre-communicated inter-world and can serve as an affordance in the environment. For Edward, Jim, and Amanda, the new activity affordance 
appears to be more important than who is participating. For this reason they frequently switch between those they are with.

The body movements in these children's play may be understood in relation to their search for interaction with the world in which they live: that is, interaction with the physical environment and interaction with other human beings. Their spontaneous body movements can be interpreted as a way to fulfil their search for interaction. This article emphasises interactions with the others. Another article related to the current project focuses on the child's interaction with the activity place.

\section{Concluding Remarks}

This article investigates how body movement in children's play is related to the children's interaction with others. The relationship emerges clearly when the body movements are interpreted in light of intersubjectivity. The children emphasise that play that includes body movement with friends is important for their experience of a meaningful ASP time. The observations reveal that such activities are typical for the ASP hours when the children have opportunities to chose and manage their own activities outdoors. Body movement seems to arise from play situations where the children spontaneously seek interaction with others. The extensive activity may also contribute to the children's health and development.

Body movement gives the children an opportunity to achieve recognition through expression. This is an intersubjective interaction where the active child immediately and spontaneously communicates skills and daring, and the observer communicates degrees of recognition. Body movement also gives the children an opportunity to interact in best-friends groups and in groups that come together as they all enjoy undertaking the same activity. The play activities in the best-friends groups emerge from mutual processes between the participants, while participation in the activity groups is determined by the choice of play activity. These forms of bodily communication occur frequently during the ASP hours when the children are outdoors and choose and manage their activities themselves.

Body movement in play is closely connected to its significant role in the children's interaction with others, and can be interpreted as a fulfilment of children's search for interaction. Based on the findings in this study, it is recommended that self-chosen and child-managed play outdoors be encouraged in the ASP.

The intersubjective dimensions in play appear to have a crucial significance in the lifeworld of the ASP children. Among children in the relevant age group, bodily communication is especially clear. They communicate directly and immediately through their bodies and body language. Thus, it is important that arenas exist that ensure the children's possibilities for body movements in self-chosen and child-managed play. There are reasons to believe that such arenas are few in the institutionalised everyday in which the child exists. The school is emphasised by structured programmes and adult-managed activity, and much of the leisure time is emphasised by adult-controlled leisure-time activities. As children's activities have appeared in this article, the ASP can have a complementary function to the arenas with structured and adult-controlled activities. Nevertheless, this depends upon the children's opportunity for self-chosen and childmanaged play outdoors where they can interact in best-friends and activity groups. Members of the ASP staff have important roles in relation to facilitating, initiating, and encouraging sufficient time, places, and equipment for this to occur. In addition, they have to pay attention to 
individual children who, for one reason or another, are excluded from the activities. There is need for further research that focuses on the ASP staff's role as it relates to children's play.

The findings in the study may also be used as an argument for a greater input of self-chosen and child-managed bodily activities in circumstances other than the ASP. We have seen body movement arise from children's spontaneous seeking for interaction and expression in play. Such a motivation source could also be applicable to curricular PE in primary school and in extracurricular PE. This requires, however, a willingness to recognise self-chosen and child-managed play in situations that usually are strictly managed and controlled by adults. This is an issue for further research.

\section{Acknowledgements}

The author would like to thank Professor Sigmund Loland, Associate Professor Ejgil Jespersen, the anonymous reviewers, and members of the Editorial Team for their helpful comments on earlier drafts of this article.

\section{Endnote}

1 'The Wheel', as it is popularly called, is a sling suspended from a pulley (the wheel) on a wire line between two poles. The poles are about 25 meters apart; one is higher than the other. The child drags the pulley to the higher frame, climbs a ladder, and sits in the sling. He or she is then virtually launched into space as the pulley runs down the line towards the lower pole. The lower support is so designed that when the pulley comes to abrupt halt, the child is left swinging in the sling. Altogether this is a considerable feat of daring for many children.

\section{References}

Adams, H. (2008). Expression. In R. Diprose \& J. Reynolds (Eds.), Merleau-Ponty: Key concepts (pp. 30-43). Stocksfield: Acumen.

Bengtsson, J. (2006). En livsverdenstilnærming for helsevitenskapelig forskning. In J. Bengtsson (Ed.), Å forske i sykdoms- og pleieerfaringer. Livsverdensfenomenologiske bidrag (pp. 1358). Kristiansand: Høgskoleforlaget.

Blair, S., Clark, D., Cureton, K., \& Powell, K. (1995). Exercise and fitness in childhood: implications for a lifetime of health. In C. Gisolfi \& D. Lamb (Eds.), Perspectives in exercise science and sports medicine, Vol 2: Youth, exercise and sport (pp. 401-430). New York: McGraw-Hill.

Busch, T. (2008). Existentialism: the “new philosophy.” In R. Diprose \& J. Reynolds (Eds.), Merleau-Ponty: Key concepts (pp. 30-43). Stocksfield: Acumen.

Buytendijk, F.J.J. (1988). The first smile of the child. Phenomenology \& Pedagogy, 6(1), 15-24. 
Caspersen, C., Pereira, M., \& Christenson, G. (1985). Physical activity, Exercise, and Physical Fitness: Definitions, and Distinctions for Health-Related Research. Public Health Reports, 100(2), 126-131.

Dunn, J. (2004). Children’s friendships: The beginnings of intimacy. Oxford: Blackwell.

Ekelund, U. (2002). Assessment of physical activity and energy expenditure in adolescents. Stockholm: Karolinska institutet.

Epstein, L., Paluch, R., Kalakanis, L., Goldfield, G., Cerny, F., \& Roemmich, J. (2001). How much activity do youth get? A quantitative review of heart-rate measured activity. Pediatrics, 108(3), E44.

Fattore, T., \& Turnbull, N. (2005). Theorizing representation of and engagement with children: The political dimension of child-oriented communication. In J. Mason \& T. Fattore (Eds.), Children taken seriously: In theory, policy and practice (pp. 45-57). London: Jessica Kingsley.

Frønes, I. (1998). Den norske barndommen. Oslo: Cappelens akademiske forlag.

Gadamer, H.G. (1989). Truth and method. London: Sheed and Ward.

Gallagher, S. (2001). The practice of mind: theory, simulation, or interaction? Journal of Consciousness Studies, 8(5-7), 83-108.

Gallagher, S. (2006). Moral personhood and phronesis. Moving bodies, 4(2), 31-57.

Gallahue, D.L., \& Ozmun, J.C. (2006). Understanding motor development: infants, children, adolescents, adults. Boston: McGraw-Hill.

Gibson, J.J. (1986). The ecological approach to visual perception. Hillsdale: Lawrence Erlbaum.

Giorgi, A. (1985). Sketch of a psychological phenomenological method. In A. Giorgi (Ed.), Phenomenology and psychological research (pp. 8-22). Pittsburgh: Duquesne University Press.

Greve, A. (2007). Vennskap mellom små barn i barnehagen, HiO-rapport 2007, 17. Oslo: Høgskolen i Oslo.

Green, K. (2008). Understanding physical education. London: Sage.

Haug, P. (1994). Skolefritidsordningene, bakgrunn og utvikling. In H. Liden, A. Øie, \& P. Haug (Eds.), Mellom skole og fritid (pp. 14-27). Oslo: Universitetsforlaget.

KD (2009). Lov om grunnskolen og den vidaregåande opplceringa. Viewed 10/09/2009, http://www.lovdata.no/all/nl-19980717-061.html.

Kvale, S. (1996). InterViews. London: Sage. 
Kvello, Ø., \& Wendelborg, C. (2002). Nasjonal evaluering av skolefritidsordningen. NTFrapport 2002-4, Steinkjer: Nord-Trøndelagsforskning.

Løndal, K., \& Bergsjø, C.H. (2005). Fysisk aktivitet i skolefritidsordningen. En undersøkelse i fire skolefritidsordninger i Oslo. HiO-rapport 2005, 14. Oslo: Høgskolen i Oslo.

Merleau-Ponty, M. (1964). The child’s relations with others. In J.M. Edie (Ed.), The primacy of perception and other essays on phenomenological psychology, the philosophy of art, history and politics (pp. 96-155). Evanstone: Northwestern UP.

Merleau-Ponty, M. (2002) [1962/1945]. Phenomenology of perception. C. Smith (trans.). London: Routledge.

Moss, P., Dillon, J., \& Stathan, J. (2000). The “child in need” and "the rich child”: Discourses, constructions and practices. Critical Social Policy, 20(2), 233-54.

Näsman, E. (1994). Individualisation and institutionalisation of children in today's Europe. In J. Qvortrup, M. Brady, G. Sgritta, \& H. Wintersberger (Eds.), Childhood matters: Social theory, practice and politics (pp. 165-187). Aldershot: Avebury.

Øksnes, M. (2001). Pedagogisering av barns fritid. Trondheim: DMMH/ Pedagogisk institutt NTNU.

Penney, D., \& Harris, J. (1997). Extra-curricular physical education: More of the same for the more able. Sport, Education and Society 2(1), 41-54.

Prout, A. (2005). The future of childhood. Towards the interdisciplinary study of children. London: Routledge Falmer.

Rasmussen, T.H. (1996). Kroppens filosof: Maurice Merleau-Ponty. Brøndby: Semi-forlaget.

Sheets-Johnstone, M. (1999). The Primacy of Movement. Philadelphia: John Benjamins Publishing Company. http://site.ebrary.com/lib/hio/Doc?id=10014705\&ppg=170.

Smith, S.J. (2007). The first rush of movement: A phenomenological preface to movement education. Phenomenology \& Practice 1(1), 47-75.

Van den Berg, J.H. (1952). The human body and the significance of human movement. Philosophy and Phenomenological Research, 13(1), 159-183.

Van Manen, M. (1990). Researching lived experience. Human Science for an Action Sensitive Pedagogy. Ontario: Althouse.

WHO (2002). The world health report 2000. Reducing risks, promoting healthy life. Geneva: World Health Organization.

WHO (2004). Global strategy on diet, physical activity and health. Geneva: World Health Organization. 
Zeiher, H. (2001). Children's island in space and time: The impact of spatial differentiation on children's way of shaping social life. In M. du Bois-Reymond, H. Sunker, \& H. Kruger (Eds.), Childhood in Europe: Approaches, trends, findings (pp.139-160). New York: Peter Lang.

Zeiher, H. (2002). Shaping daily life in urban environments. In P. Christensen \& M. O’Brien (Eds.), Children in the city: Home, neighbourhood and community (pp. 66-81). London: Falmer press. 